\title{
BMJ Open Evidence available for patient-identified priorities in depression research: results of 11 rapid responses
}

\author{
Meghan Sebastianski, ${ }^{1}$ Michelle Gates, ${ }^{\circ} 2$ Allison Gates, ${ }^{\circ} 2$ Megan Nuspl, ${ }^{1}$ \\ Liza M Bialy, ${ }^{1}$ Robin M Featherstone, ${ }^{1,2}$ Lorraine Breault, ${ }^{3}$ Ping Mason-Lai, ${ }^{4}$ \\ Lisa Hartling ${ }^{1,2}$
}

\begin{abstract}
To cite: Sebastianski M, Gates M, Gates A, et al. Evidence available for patient-identified priorities in depression research: results of 11 rapid responses. BMJ Open 2019:9:e026847. doi:10.1136/ bmjopen-2018-026847

- Prepublication history and additional material for this paper are available online. To view these files, please visit the journal online (http://dx.doi. org/10.1136/bmjopen-2018026847).
\end{abstract}

Received 26 September 2018 Revised 7 March 2019 Accepted 11 June 2019

Check for updates

(c) Author(s) (or their employer(s)) 2019. Re-use permitted under CC BY-NC. No commercial re-use. See rights and permissions. Published by BMJ.

For numbered affiliations see end of article.

Correspondence to

Lisa Hartling;

hartling@ualberta.ca

\section{ABSTRACT}

Objectives Patient priority setting projects (PPSPs) can reduce research agenda bias. A key element of PPSPS is a review of available literature to determine if the proposed research priorities have been addressed, identify research gaps, recognise opportunities for knowledge translation (KT) and avoid duplication of research efforts. We conducted rapid responses for 11 patient-identified priorities in depression to provide a map of the existing evidence.

Design Eleven rapid responses.

Data sources Single electronic database (PubMed). Eligibility criteria Each rapid response had unique eligibility criteria. For study designs, we used a stepwise inclusion process that started with systematic reviews (SRs) if available, then randomised controlled trials and observational studies as necessary.

Results For all but one of the rapid responses we identified existing SRs (median 7 SRs per rapid response, range $0-179$ ). There were questions where extensive evidence exists (ie, hundreds of primary studies), yet uncertainties remain. For example, there is evidence supporting the effectiveness of many non-pharmacological interventions (including psychological interventions and exercise) to reduce depressive symptoms. However, targeted research is needed that addresses comparative effectiveness of promising interventions, specific populations of interest (eg, children, minority groups) and adverse effects.

Conclusions We identified an extensive body of evidence addressing patient priorities in depression and mapped the results and limitations of existing evidence, areas of uncertainty and general directions for future research. This work can serve as a solid foundation to guide future research in depression and KT activities. Integrated knowledge syntheses bring value to the PPSP process; however, the role of knowledge synthesis in PPSPs and methodological approaches are not well defined at present.

\section{INTRODUCTION}

Worldwide, an estimated 300 million people suffer from depression, a mental health disorder that is the primary contributor to global disability. ${ }^{1}$ Although more prevalent in older female adults, depression can affect

\section{Strengths and limitations of this study}

- We provide a summary of the existing evidence for 11 patient-identified priority topics in depression research based on rigorous and transparent review methods.

- Our application of rapid review methods is a novel approach to verify uncertainties arising from a patient priority setting project (PPSP)

- This work provides a solid foundation to specify future depression research needs and knowledge translation activities.

- Our lessons learnt from conducting knowledge syntheses for a PPSP will help inform this aspect of the James Lind Alliance methods.

- Further work on whether and how to involve patients in the literature review aspect of a PPSP would be beneficial to ensure their perspectives are integrated throughout the process.

all ages, sexes and ethnicities. ${ }^{12}$ For the individual, depression negatively affects physical health and well-being, leading to a reduced quality of life while exerting a considerable financial burden on society due to lost productivity, workplace absenteeism and healthcare costs. ${ }^{2-6}$

Historically, the research agenda has not aligned with patient priorities; research agendas are often biased towards commercial interests of funders and personal interests of researchers. ${ }^{7}$ For example, registered trials comparing drug efficacies are much more common than those comparing drugs to non-drug therapies $(86.3 \%$ vs $2.6 \%)$, such as antidepressants versus psychotherapy, which may be of more interest to patients. ${ }^{7}$ Recently, numerous initiatives have been launched to incorporate the patient voice in health research. $^{8-10}$

Involving patients with lived experience in research priority setting aids in ensuring research agendas reflect the interests of both patients and researchers, increasing the 


\begin{tabular}{ll}
$\begin{array}{l}\text { 1. Which treatment therapy or method is more } \\
\text { successful for long term remission or recovery? }\end{array}$ & $\begin{array}{l}\text { 7. Can diet or exercise affect the development of } \\
\text { depression? }\end{array}$ \\
$\begin{array}{ll}\text { 2. What are the long term physical implications of } \\
\text { pharmacotherapy for treating depression? }\end{array}$ & $\begin{array}{l}\text { and psychological problems experienced by children } \\
\text { and teens living with an immediate family member } \\
\text { who has depression? }\end{array}$ \\
$\begin{array}{ll}\text { 3. For various treatment options (e.g. psychotherapy, } \\
\text { individual vs. group psychotherapy and psychosocial }\end{array}$ & $\begin{array}{l}\text { 9. What interventions are effective in preventing and } \\
\text { treating workplace depression and reducing stigma }\end{array}$ \\
$\begin{array}{l}\text { support), what are the advantages in terms of cost, } \\
\text { associated with depression in the workplace? }\end{array}$ \\
$\begin{array}{ll}\text { 4. What are the prevention strategies/tactics for } \\
\text { reducing self-harm and suicide in children, youth and } \\
\text { adults with depression? }\end{array}$ & $\begin{array}{l}\text { 10. Are there structural or functional changes in the } \\
\text { brain due to antidepressant therapy during brain } \\
\text { development? }\end{array}$ \\
$\begin{array}{ll}\text { 5. What changes to the health care system will } \\
\text { increase access to psychological services? }\end{array}$ & $\begin{array}{l}\text { 11. What is the role of family in the treatment and } \\
\text { trajectory of depression? }\end{array}$ \\
$\begin{array}{l}\text { 6. What changes in the health care system will result } \\
\text { in shortened wait times for depression services? }\end{array}$ & \\
\hline
\end{tabular}

use and value of subsequent knowledge generation and translation. ${ }^{711}{ }^{12}$ With this in mind, the Alberta Strategy for Patient-Oriented Research (SPOR) SUPPORT Unit Patient Engagement Platform, in partnership with the Alberta Health Services Addictions and Mental Health Strategic Clinical Network and the Canadian Depression Research and Intervention Network, undertook the Alberta Depression Priority Setting Project (ADPSP). The aim of the project was to identify Albertans' top research priorities in the area of depression. The ADPSP adapted the James Lind Alliance (JLA) Priority Setting Partnership method to guide the process; detailed methods and results are described elsewhere. ${ }^{13}{ }^{14}$ In summary, the ADPSP undertook five steps: identification of a topic and assembly of participants, gathering of research priorities from a public survey, consolidation of proposed priorities, ranking through a second public survey and a final prioritisation process to produce a list of top 11 priorities in depression research (figure 1).

A key element of any patient priority setting process is a literature review to determine if the proposed research priorities have been previously answered. ${ }^{15}$ The Knowledge Translation (KT) Platform of the Alberta SPOR SUPPORT Unit undertook a series of rapid responses to examine the extent and nature of existing evidence relating to the ADPSP's top 11 priorities. The goal was to identify research gaps, recognise opportunities for KT and prevent duplication of research efforts. The purpose of this paper is to detail the available evidence for the patient-identified priorities in depression and to discuss our approach to knowledge synthesis in the context of a patient priority setting project (PPSP).

\section{METHODS}

We used rapid review methodology adapted from available guidelines ${ }^{16}$ as it is best suited for reviewing a large body of evidence in a short amount of time. As a first step, we worked with the ADPSP colead who was directly involved in the PPSP to identify the PICO components (population, intervention, comparison, outcome) of the priorities and generate researchable questions to guide our syntheses, which is consistent with guidance for conducting PPSPs. ${ }^{15}$ We undertook 11 rapid responses of nine priorities suitable for knowledge synthesis. One of the priorities (\#3, figure 1) was multifaceted and divided into three subquestions, and two health services questions (\#5 and \#6, figure 1) were better answered by internal health systems data. Table 1 details each rapid response question, inclusion and exclusion criteria.

\section{Search}

Search methods vary for the breadth of available rapid reviews approaches. ${ }^{17}$ While the JLA recommends the Cochrane Database of Systematic Reviews and a number of guideline centres, it does not require particular database sources. In consultation with an information specialist, we decided to search PubMed (MEDLINE) as our primary source of evidence as the database indexes reviews (including Cochrane systematic reviews (SRs)), guidelines and trials and provides broad coverage of depression research with over 25 million references to journal articles in life sciences, with a concentration on

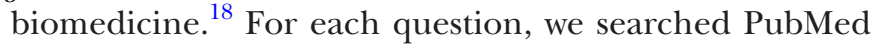
via NCBI Entrez (1946-current) for key concepts (table 1). To moderate the resources required to review a large body of evidence, we determined a priori to filter the available evidence based on hierarchies of evidence and relevance of the study design to the research question. The JLA recommends verifying uncertainties with SRs and adding additional sources with robust methodologies as needed. ${ }^{15}$ We started with SRs, then randomised controlled trials (RCTs) and observational (non-randomised) studies. JLA also suggests using up-to-date evidence which has been published in the last 3 years, while the rapid review guidelines we adapted suggest a 5 year date range. ${ }^{16}$ We extended it to 10 years to be overly inclusive. Search results were limited to English-language publications from 2007 and were executed for each question between July and October 2017. The search strategies 


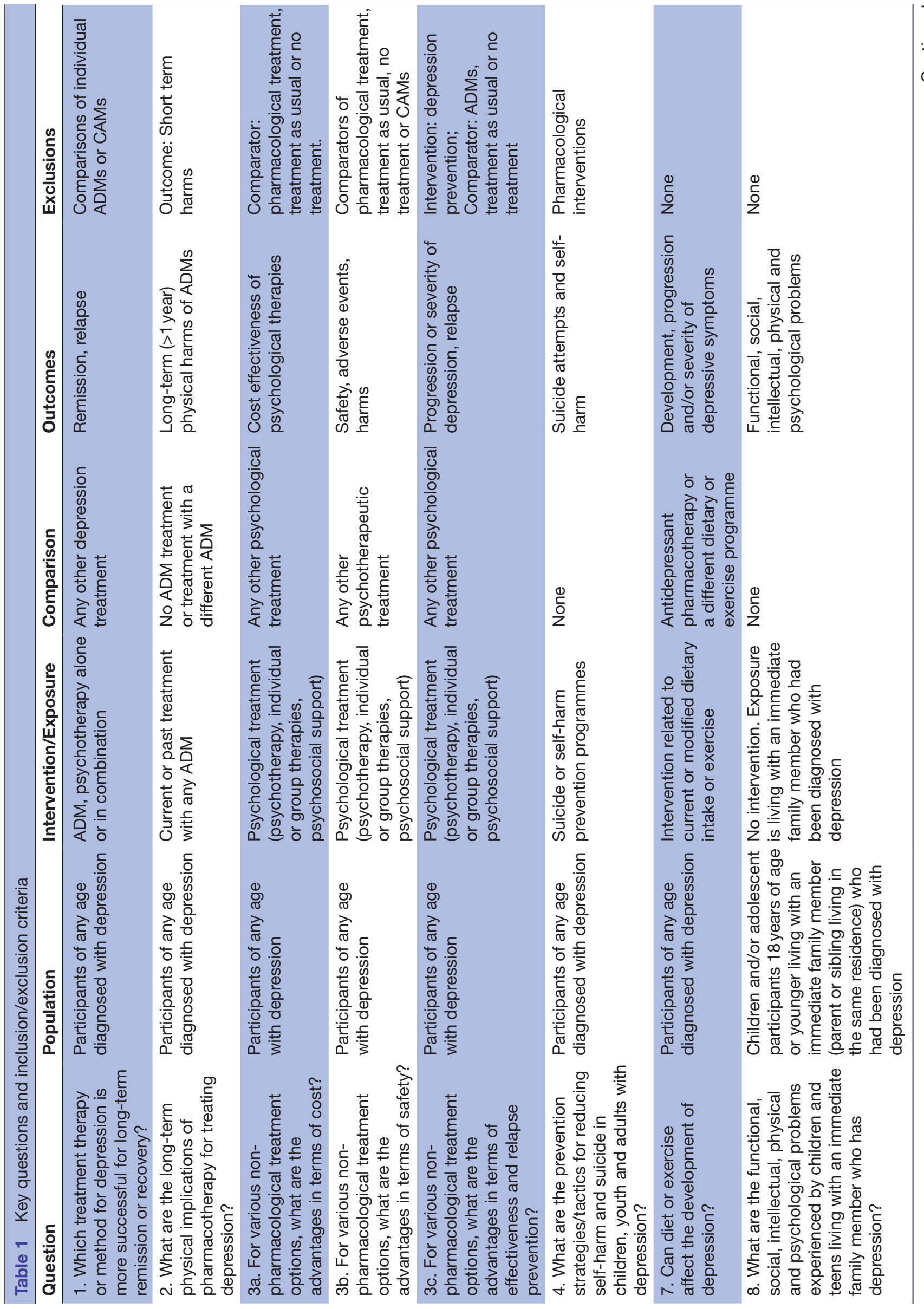




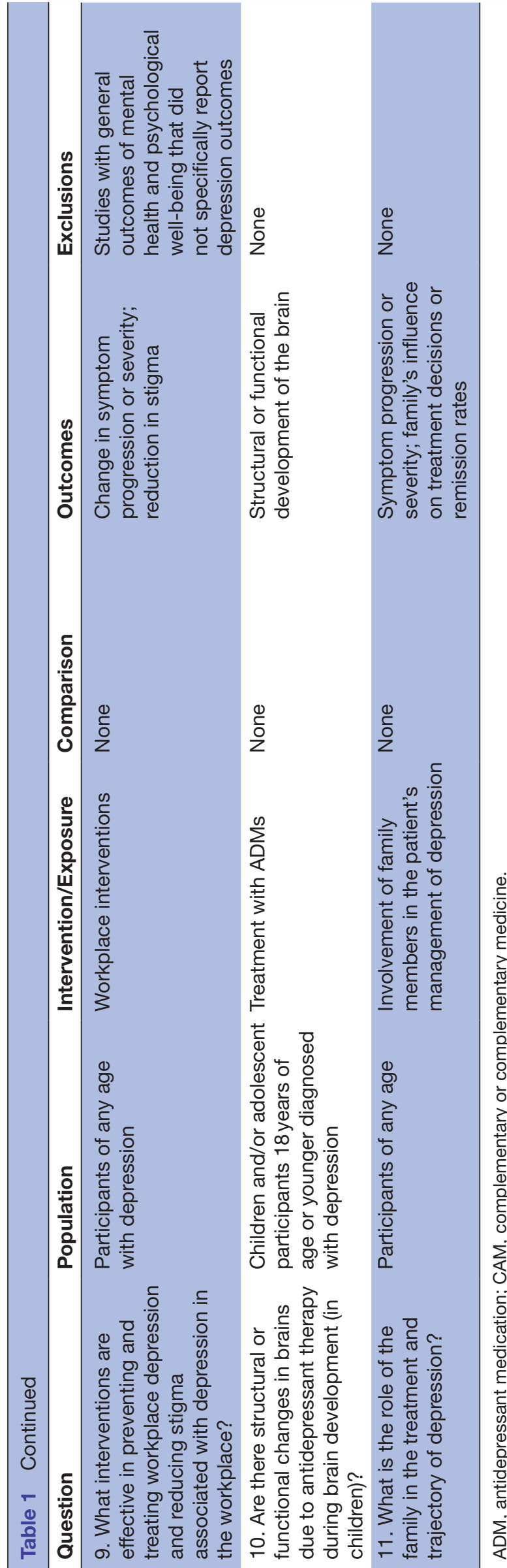

are available in online supplementary appendix 1 . Records were managed in EndNote X7 (Clarivate Analytics, Philadelphia, Pennsylvania) and screened in Microsoft Office Excel 2016 (Microsoft, Redmond, Washington, USA).

\section{Study selection}

For eight rapid responses, we undertook staged screening by study design (SRs first, then RCTs, then observational studies) dependent on the quantity and level of evidence identified at each stage (figure 2). For three rapid responses, we screened all study designs. Primary screening (title and abstract) followed by secondary full text screening was done by a single reviewer based on a priori eligibility criteria (ie, patient characteristics, intervention/exposure, comparisons and outcome measures) (table 1).

\section{Data extraction and quality assessment}

Key study characteristics, general findings and conclusions were extracted by a single reviewer. Included studies were not assessed for quality as the goal was to map all the evidence available rather than answer a specific question based on the best available evidence ${ }^{19}$ however, author-reported study limitations were extracted and included in the summary tables.

\section{Data synthesis}

We synthesised the findings narratively and in tabular format and presented conclusions in terms of the quantity and level of the existing evidence and future research needs/priorities.

\section{Patient involvement}

Persons with lived experience were members of the ADPSP steering committee and 445 members of the public responded to the ADPSP survey. While the depression research priorities identified by the ADPSP were the foundation of the rapid responses, patients were not involved in the knowledge synthesis process which is consistent with PSP guidance. ${ }^{15}$

\section{RESULTS}

Across the 11 rapid responses, we included 158 studies and identified existing SRs for all but one of the questions (median 7 SRs per rapid response, range 0-179) (figure 2). A narrative summary of the findings of each rapid response is presented below. The conclusions and limitations of the existing evidence and future research needs/priorities are outlined in table 2; details of each included study are available in online supplementary appendix 2.

Q1. Which treatment therapy or method for depression is more successful for long-term remission or recovery?

Remission

The evidence did not support a difference in remission rates among patients treated with antidepressant medication (ADM) compared with cognitive behavioural therapy 


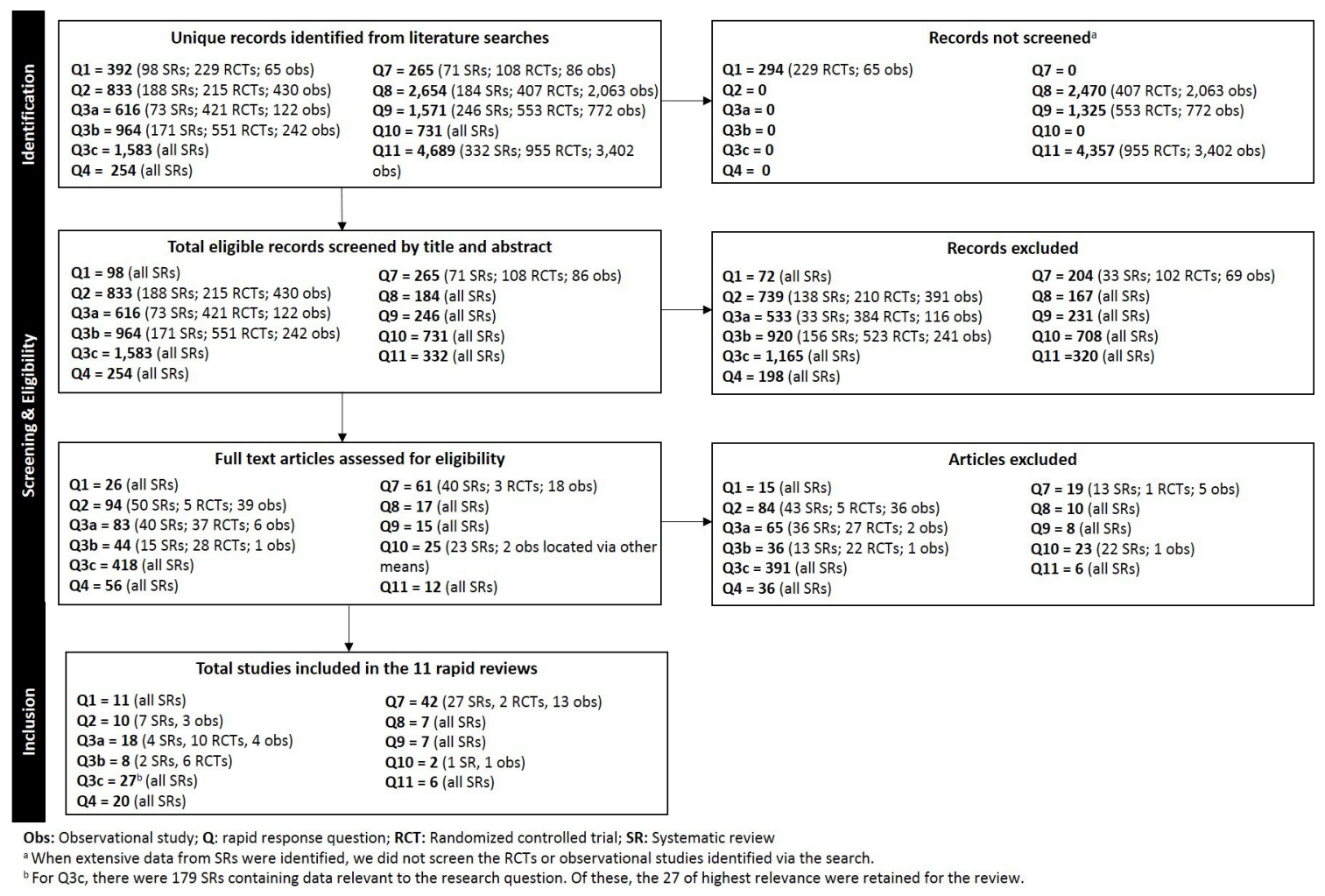

Figure 2 Flow diagram of screening decisions. RCTs, randomised controlled trials; SRs, systematic reviews.

(CBT),${ }^{20-22}$ interpersonal psychotherapy, ${ }^{20} 21$ psychodynamic therapy ${ }^{21}$ or combination therapies (ADM and $\mathrm{CBT}){ }^{21}$ One review reported there was insufficient evidence to draw conclusions about ADM effectiveness compared with third-wave CBT. ${ }^{21}$ Two reviews found no difference in remission rates between patients with treatment-resistant depression who: were treated with ADM or psychotherapy; ${ }^{23}$ switched from ADM to a new ADM or to cognitive therapy $(\mathrm{CT})^{21}$ or augmented ADM with a new ADM or with CT. ${ }^{21}$ For children and adolescents, there was insufficient evidence to determine the most effective treatment to induce remission. ${ }^{24}$

\section{Relapse prevention}

Reduction in relapse risk was found among patients treated with ADM compared with psychotherapy; ${ }^{25}$ with psychotherapy (alone or in combination with $\mathrm{ADM}$ ) after response to $\mathrm{ADM} ;{ }^{26}$ and with augmentation of treatment as usual (with or without $\mathrm{ADM}$ ) with mindfulness-based cognitive therapy (MBCT) ${ }^{27}$ One review found no difference between maintenance $\mathrm{ADM}$ and $\mathrm{MBCT}^{28}{ }^{8}$ For children and adolescents, increased relapse risk was reported among patients treated with $\mathrm{ADM}$ alone compared with $\mathrm{ADM}$ with $\mathrm{CBT}^{29}$

\section{Q2. What are the long-term physical implications of pharmacotherapy for treating depression?}

The observational $\mathrm{SR}^{30-34}$ findings support a relationship between ADM use and risk of incident fracture that appears to be independent of bone mineral density. Persistence of risk over time is unclear. ${ }^{30}$ One $\mathrm{SR}^{35}$ supported an association between ADM use and incident diabetes, and another ${ }^{36}$ associated certain ADMs with weight gain, cardiovascular events and fractures. Two cohort studies $^{3738}$ support an association between ADM use and incident cardiovascular risk factors, while one cohort study ${ }^{39}$ did not support any association between ADM use and incident hepatocellular carcinoma in adults with hepatitis C.

Q3a. For various non-pharmacological treatment options, what are the advantages in terms of cost?

Considerable heterogeneity in the types of therapies researched precluded meaningful synthesis. The included studies examined 16 different therapies: behavioural activation, ${ }^{40}{ }^{41} \mathrm{CBT}^{41-54}$ general counselling, ${ }^{43}$ person-centred therapy, ${ }^{50}$ problem-solving therapy, ${ }^{54}$ psychoanalysis, ${ }^{45}{ }^{55}$ psychoanalytic psychotherapy, ${ }^{55}$ psychoeducation, ${ }^{48}{ }^{56}$ CBT-enhanced psychoeducation, ${ }^{48}$ psychologist-enhanced psychoeducation, ${ }^{48}$ short-term ${ }^{48}{ }^{57}$ and long-term ${ }^{57}$ psychodynamic therapy, psychosocial therapy ${ }^{45}$ relaxation therapy, ${ }^{42}$ self-management therapy ${ }^{56}$ and solution-focused therapy. ${ }^{48}$ The $\mathrm{SRs}^{42} 434851$ each included zero to three studies with relevant comparisons that presented economic data.

Across all 18 included studies, there were 22 different cost effectiveness comparisons; two SRs each included three $^{45}$ and four ${ }^{48}$ relevant comparisons, and only two primary studies investigated the same comparison (telephone vs in-person CBT) ${ }^{4647}$ There were two SRs, ${ }^{4251}$ three RCTs $^{44464795253}$ and three observational studies ${ }^{44465}$ that focused specifically on various approaches to the delivery 


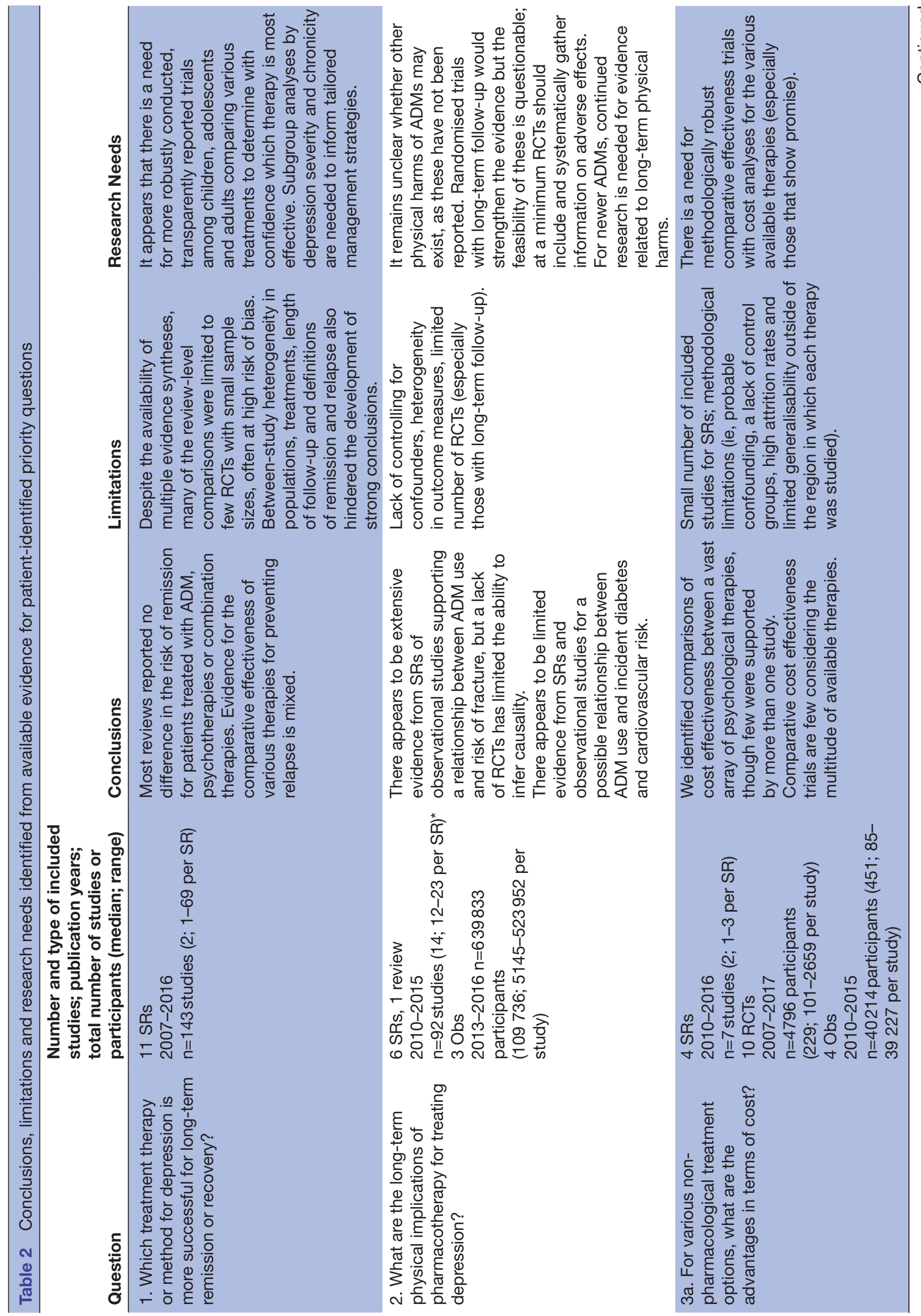




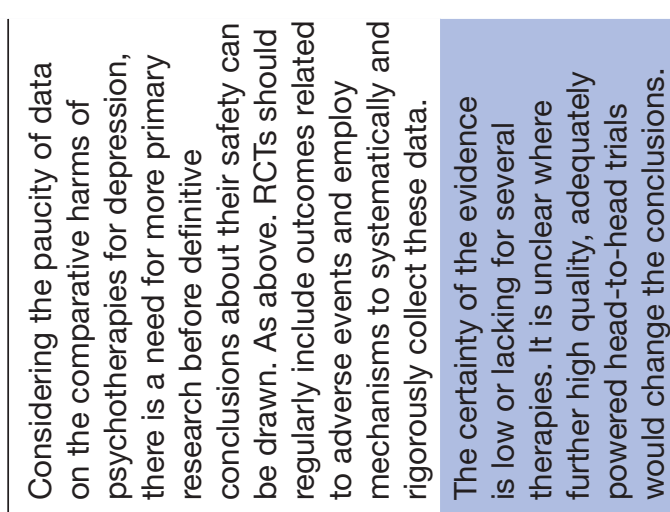

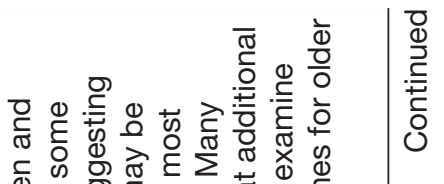

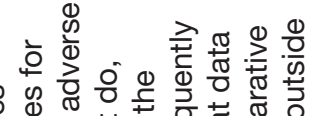
⿻

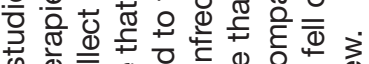

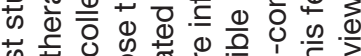
获

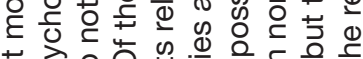
त

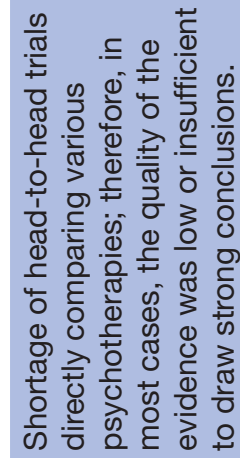

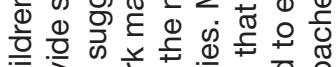
论

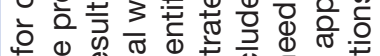

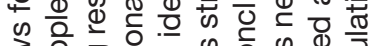

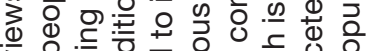

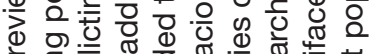

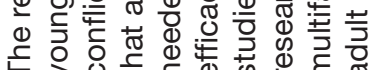

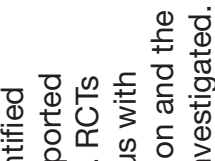

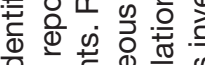

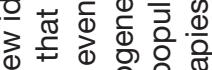
\& $₫$ 흥 क क त क्ष

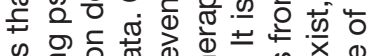
는 응 $\frac{0}{1}$

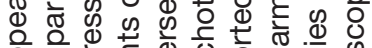

定

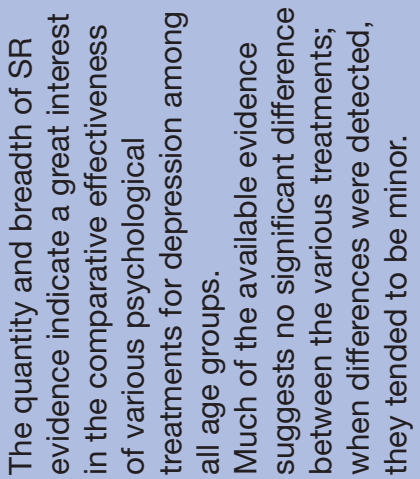

.

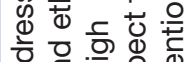

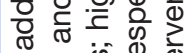

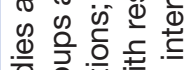

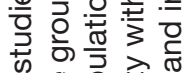

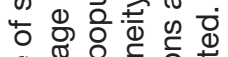

芩

吉迹通过

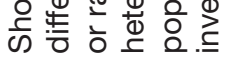

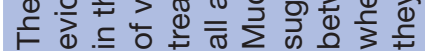

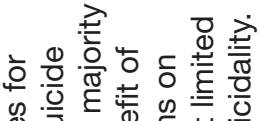

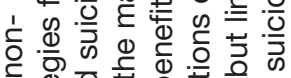

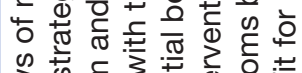

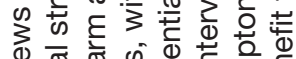

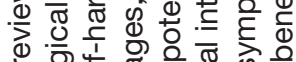
ब

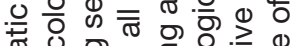

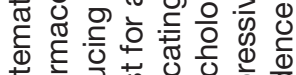

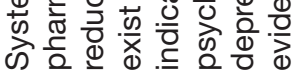
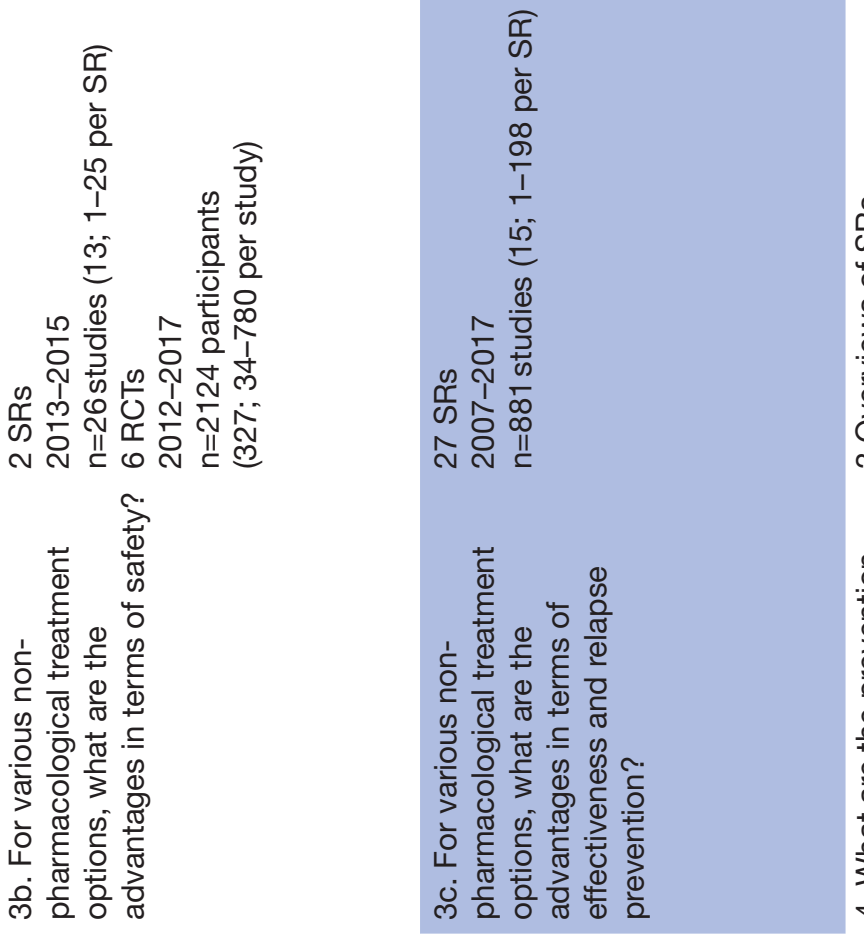

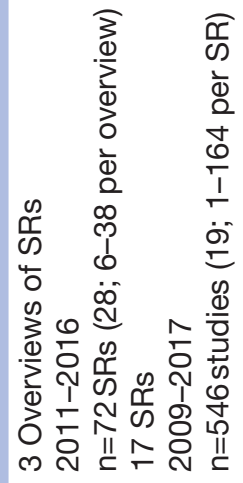

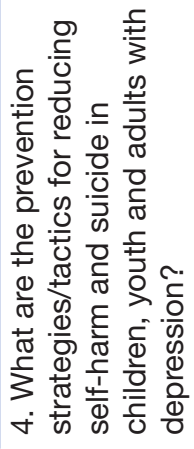




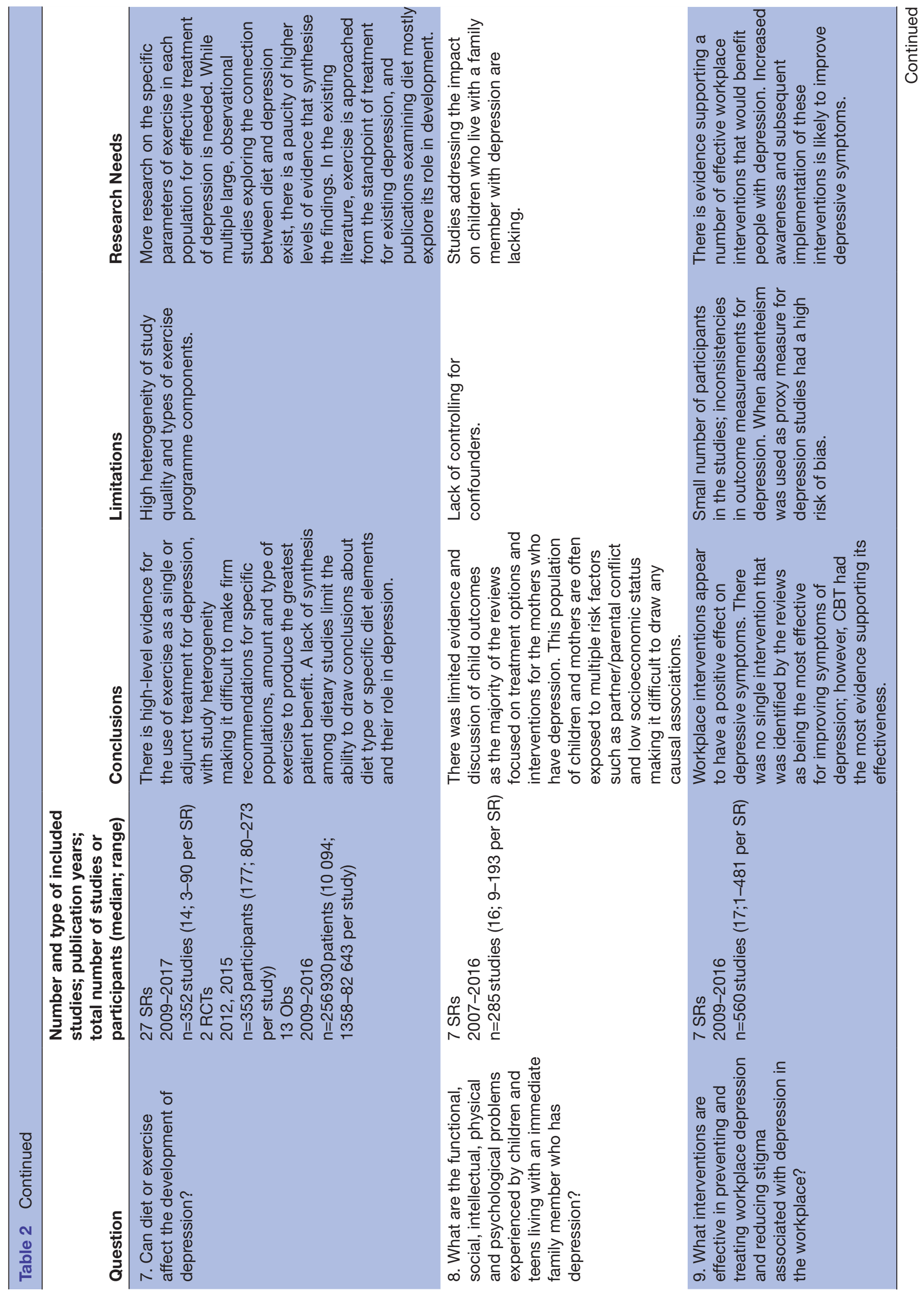




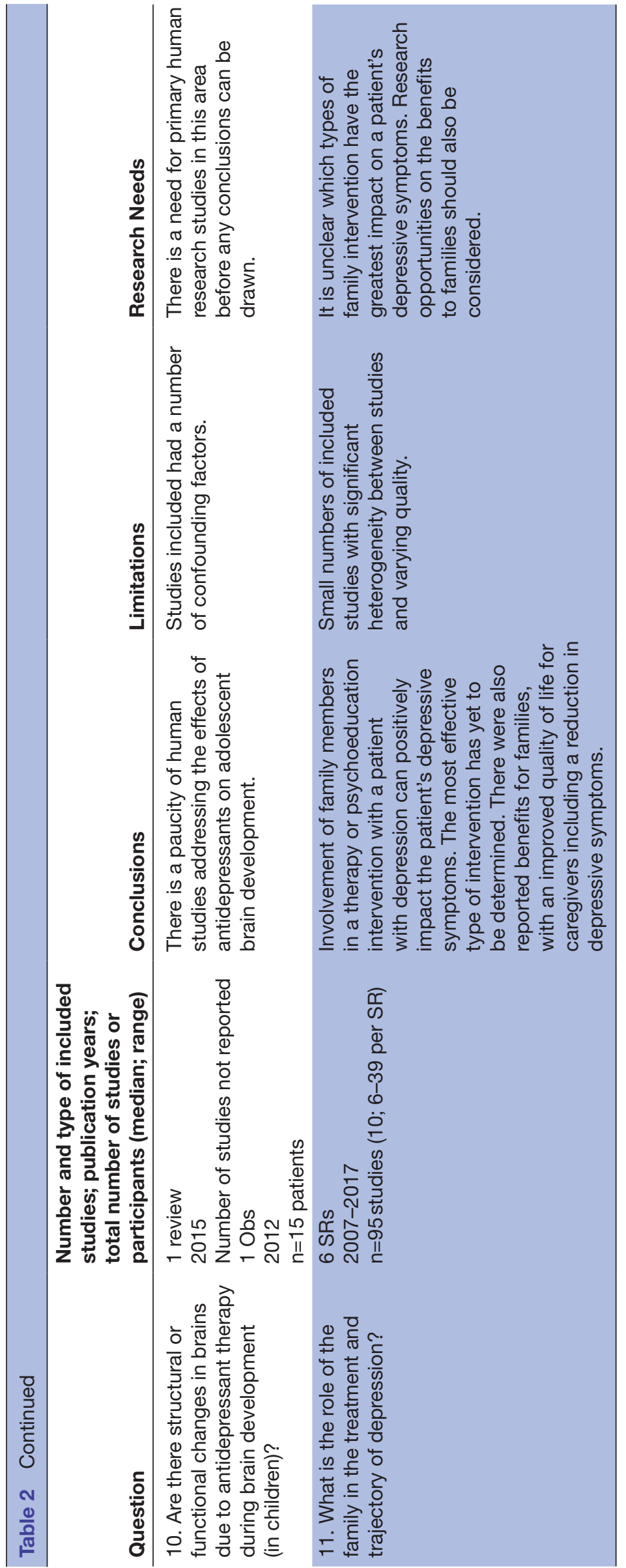

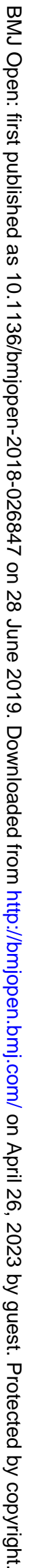


of CBT. Overall, the RCTs and observational studies were hindered by numerous methodological limitations, and given the disparate nature of the comparisons it is not possible to draw conclusions about the comparative cost effectiveness of various treatment options.

\section{Q3b. For various psychotherapeutic treatment options, what are the advantages in terms of safety?}

One SR investigated CBT compared with supportive psychotherapy for adults with depression following traumatic brain injury. ${ }^{58}$ Another SR investigated behavioural therapy compared with other psychotherapies for adults with depression. ${ }^{59}$ Neither SR identified studies that reported adverse events.

The RCTs were heterogeneous with respect to population and psychotherapies investigated. Populations included adolescent and adult inpatients and outpatients with depression, with and without comorbid conditions. Psychotherapeutic treatments included behavioural activation, ${ }^{41}{ }^{60}$ counselling, ${ }^{61}$ various forms of CBT, ${ }^{41}$ 61-64 psychoanalytical therapy ${ }^{63}$ and psychosocial interventions. ${ }^{63}$ Two RCTs investigated psychotherapies delivered via different means. ${ }^{60} 64$

One RCT reported no difference in adverse events between a brief psychosocial intervention, CBT and short-term psychoanalytical therapy groups. ${ }^{63}$ Another RCT reported adverse events that were possibly or probably related to the psychotherapies. ${ }^{61}$ Mild adverse events were reported in the computerised CBT group $(n=1)$ and the face-to-face CBT group $(n=2)$; eight moderate adverse events (eg, increased suicidal thinking) were reported in each group. Serious adverse events (suicide attempts) were reported in the computerised CBT group $(n=2)$ and the face-to-face CBT group $(n=1)$. No other adverse events were reported.

\section{Q3c. For various non-pharmacological treatment options,} what are the advantages in terms of effectiveness and relapse prevention?

Included SRs ${ }^{58} 5965-89$ mainly compared psychotherapy or CBT versus other psychotherapies across several populations (eg, children, adolescents, adults, postpartum, older adults). There were also comparisons for varied treatment modalities (eg, online vs face-to-face), formats (eg, individual vs group) and level of therapist training. With some exceptions, the available evidence suggests no significant difference between the treatments under study for post-treatment effectiveness (ie, symptom reduction), remission and continued effectiveness at varying lengths of follow-up (ie, relapse prevention). When differences were noted, the effect estimates were usually small and imprecise.

Despite the large number of SRs, they were limited by a shortage of trials directly comparing various psychotherapies; some therapies were left out entirely. There was less evidence for long-term treatment effects and questions remain about which patients would be best suited to the various treatments.
Q4. What are the prevention strategies/tactics for reducing self-harm and suicide in children, youth and adults with depression?

Children, adolescents and young adults

Eight reviews ${ }^{90-97}$ examined interventions grouping children, adolescents and young adults ( $\leq 24$ years). One $\mathrm{SR}^{96}$ found that interpersonal psychotherapy reduced depressive symptoms in adolescents, but did not impact suicide. Three reviews ${ }^{90} 9194$ examined school-based interventions for suicide reduction; two overviews ${ }^{90}{ }^{91}$ found some benefit to school-based strategies, while one $\mathrm{SR}^{94}$ found few studies examining this type of intervention and was unable to draw conclusions. Three SRs ${ }^{92} 9397$ examined psychological interventions. One ${ }^{92}$ concluded that psychological strategies hold promise as a suicide prevention strategy in this population; one ${ }^{93}$ found minimal support for group-based therapy, while the other ${ }^{97}$ argued that group-based therapy might be effective in suicide prevention. One $\mathrm{SR}^{95}$ examined online and mobile application interventions and could not draw strong conclusions from the single included study.

Adults

Four SRs ${ }^{98-101}$ investigated interventions aimed at preventing self-harm and suicide in adults. Two ${ }^{99} 100$ found that CBT and dialectical behaviour therapy may be effective at preventing and reducing self-harm in those with previous episodes. One ${ }^{98}$ was unable to draw conclusions on the effectiveness of psychotherapy for suicidality, and one ${ }^{101}$ found CBT to be an effective treatment for depressive symptoms, but did not have a clear effect on suicidality.

\section{Older adults}

Two SRs ${ }^{102} 103$ addressed suicidality in older populations ( $\geq 60$ years). Both found that multifaceted primary care interventions were effective in reducing suicidal behaviour, with one ${ }^{102}$ reporting a greater effect in women.

\section{All ages; age not indicated}

Six reviews ${ }^{104-109}$ targeted multiple age groups or did not specify the age group. One $\mathrm{SR}^{104}$ found text messaging interventions were effective in patients contemplating suicide. Three $\mathrm{SRs}^{105-107}$ found psychotherapy-based interventions to be an effective treatment of patients with depression or contemplating suicide, though one $\mathrm{e}^{107}$ noted that the effect did not carry over to adolescents. Two reviews ${ }^{108} 109$ concluded that more research is needed on combined therapies to determine the potential synergistic benefits of a multifaceted approach.

\section{Q7. Can diet or exercise affect the development of depression? Diet}

We identified evidence for the role of diet in the treatment or prevention of depression from 2 narrative reviews ${ }^{110} 111$ and 13 observational studies. ${ }^{12-124}$ One review $^{110111}$ found that the importance of good nutrition for mental health is supported in the literature, especially 
for older populations, and the second ${ }^{110}$ found that Western diets might be associated with a higher risk of depression. Of the observational studies, two studies ${ }^{113} 116$ reported that dietary patterns were not associated with depression risk or development, but one ${ }^{116}$ noted that overall caloric intake was inversely related to depression in older people. Three studies ${ }^{121-123}$ found that moderate adherence to a certain diet type was associated with lower rates of depression. The remaining studies investigated specific nutrients. Five studies ${ }^{114}$ 118-120 124 examined fish or the consumption of specific fatty acids. One ${ }^{120}$ reported no association between fat intake and depression; another ${ }^{119}$ found no relationship between omega-3 polyunsaturated fatty acids (PUFA) and depression, but reported an inverse relationship between $\alpha$-linoleic acid and depressive symptoms. Two studies ${ }^{114} 118$ reported an inverse relationship between depression risk and fish consumption. One study ${ }^{123}$ found that higher trans fatty acid consumption was associated with a higher risk of depression, as well as an inverse association between monounsaturated fatty acids, PUFA or olive oil consumption and depression. Of the remaining studies, one $\mathrm{e}^{117}$ found no association between zinc intake and depression risk, one ${ }^{115}$ found a moderate positive relationship between dietary fibre intake and depression rates and one ${ }^{112}$ reported that higher flavonoid intake may decrease the risk of developing depression.

\section{Exercise and depression}

Twenty-five SRs ${ }^{125-151}$ provided evidence regarding the role of exercise in the treatment or prevention of depression. Two SRs focusing on adolescents with depression $^{125}{ }^{142}$ found exercise to be effective in reducing depression symptoms. Three SRs found exercise effective for depressive symptoms in elderly patients, with one concluding that exercise had a large antidepressant effect, ${ }^{149}$ one finding no difference between exercise and antidepressant drugs ${ }^{147}$ and the third finding exercise in conjunction with antidepressants to be effective in elderly patients with treatment resistant depression. ${ }^{137}$ Two reviews looked at exercise for depression in special populations, with one finding reduced symptoms in pregnant women, ${ }^{151}$ and the other finding the same result in patients with chronic disease. ${ }^{132}$ Three reviews found exercise to be effective as an adjunct to other therapy, including pharmacological or psychosocial. ${ }^{127} 138144$ Two reviews ${ }^{133} 136$ did not find sufficient evidence to suggest a benefit of exercise. The remaining reviews found exercise a favourable intervention in terms of symptom reduction or relapse prevention, with exercise providing additional benefit over no treatment or demonstrating no difference from pharmacological or psychological treatments. $126128130135139-141143148$

\section{Diet, exercise and depression}

Two RCTs ${ }^{129} 150$ examined interventions with both dietary and exercise components. The first ${ }^{129}$ was a pilot of the later study. ${ }^{150}$ While the pilot study found that specific lifestyle recommendations were an effective complement to antidepressant therapy, ${ }^{129}$ the larger study did not find the same association. ${ }^{150}$

Q8. What are the functional, social, intellectual, physical and psychological problems experienced by children and teens living with an immediate family member who has depression? Two SRs ${ }^{152} 153$ and a meta-analysis ${ }^{154}$ found children had significantly higher IQ scores if their mothers were not diagnosed with postnatal depression. For children with a depressed family member, one $\mathrm{SR}^{153}$ reported either weak or no evidence for all outcomes while another $\mathrm{SR}^{152}$ reported that maternal depression was more strongly associated with internalising problems than with negative or positive emotion/behaviour, and with children's general psychopathology than with externalising problems and negative or positive emotion/behaviour.

Four SRs reported on a variety of outcomes. One ${ }^{155}$ suggested that chronic maternal depression may play an important role in a child being overweight while another ${ }^{156}$ reported that when maternal depression exists, early childhood aggression is more likely to occur. Parental prenatal and postnatal depression was found to be responsible for increasing the mean rate of behavioural and emotional problems ${ }^{157}$ and antenatal depression was found to affect children's conduct problems and antisocial behaviours. ${ }^{158}$

Q9. What interventions are effective in preventing and treating workplace depression and reducing stigma associated with depression in the workplace?

Five SRs ${ }^{159-163}$ measuring depression directly reported that workplace interventions showed positive effects on depression severity, with one meta-analysis ${ }^{163}$ indicating a small effect size. No single intervention was identified as being the most effective for improving symptoms of depression; however, CBT had the most evidence supporting its effectiveness. ${ }^{159} 160$

Workplace absenteeism was used as a proxy depression measure in two reviews. ${ }^{164}{ }^{165}$ One review ${ }^{164}$ of workers with major depressive disorder or high levels of depressive symptoms reported that combining a work-directed intervention with a clinical intervention decreased sickness absences. In contrast, an earlier review ${ }^{165}$ found insufficient evidence to determine effectiveness of workplace interventions on absenteeism in depressed employees due to high risk of bias and very low quality evidence. We did not find any reviews addressing stigma.

\section{Q10. Are there structural or functional changes in brains} due to antidepressant therapy during brain development (in children)?

One narrative review ${ }^{166}$ reported that research of the effects of ADM on adolescent brain development was limited to animal models and treatment decisions were often based on adult-specific studies. A prospective cohort study $(\mathrm{n}=15)^{167}$ supported the use of fluoxetine to achieve normal brain activity in adolescents with depression. 
Q11. What is the role of the family in the treatment and trajectory of depression?

Four reviews ${ }^{76} 168-170$ addressed populations where the main diagnosis was depression. Three $\mathrm{e}^{168-170}$ of these reviews reported that interventions including one or more family members led to improved depressive symptoms in the patient. The remaining review ${ }^{76}$ found that while family therapy appears to be more effective than no treatment, the certainty of its effectiveness is unclear. Two ${ }^{171} 172$ additional reviews addressed changes in depressive symptoms through family involvement where depression was an outcome of the primary disease diagnosis. For patients with cancer, couple-based interventions, particularly psychoeducation interventions, led to significant improvements in patients' depression scores, ${ }^{172}$ while family-orientated intervention was effective at reducing depression in patients poststroke. ${ }^{171}$ Three reviews ${ }^{168} 171172$ also reported the interventions benefited patients' families, with an improved quality of life for caregivers including reduced depressive symptoms.

\section{DISCUSSION}

An extensive volume of research relating to depression addresses, either in whole or in part, the 11 research questions that arose from the ADPSP. The extent of available research underscores the importance of this mental health disorder and its far-reaching impact. This mapping of the evidence provides a strong and critical foundation to guide future research and KT opportunities.

Among the patient-identified priorities, there are questions where extensive evidence exists (ie, hundreds of primary studies), yet uncertainties remain. It might be tempting to conclude that 'more research is needed'; however, a close examination of what is known and what remains uncertain is critical to guide implementation of proven strategies and judicious investment in future research efforts. For example, there is evidence supporting the effectiveness of many non-pharmacological interventions (including psychological interventions and exercise) to reduce depressive symptoms. However, targeted research is needed that addresses comparative effectiveness of promising interventions, specific populations of interest (eg, children, minority groups) and adverse effects. Further, attention is needed to ensure appropriate and rigorous methods and explore innovative methodologies (eg, real world evidence, pragmatic trials, big data analytics, network meta-analysis) to make the most efficient use of funds, existing research and available data.

A lack of KT was also recognised in the PPSP process. For some priorities, there is research available to answer patient-identified research priorities, yet they are still being identified as knowledge gaps. For example, cognitive behavioural therapy has evidence supporting its effectiveness in preventing and treating workplace depression. Investment in KT strategies to increase awareness and subsequent implementation of these interventions is critical and should be a priority for funding agencies and other stakeholders.

\section{Strengths}

From a service provision standpoint, application of rapid response methods enabled our team to provide the requestor with targeted evidence relating to their priorities. From a methods perspective, our approach allowed for the expedited provision of results within a tight timeframe while using transparent and reproducible methods. Last, the collaboration between our knowledge synthesis team and the PPSP furthers the likelihood that future depression research agendas represent the interests of both researchers and patients.

\section{Challenges}

We attempted to categorise the results of each rapid response as to whether further primary research, evidence syntheses or KT was needed based on the JLA definition of a treatment uncertainty. Verification of treatment uncertainties through JLA is based on the reported CI of a recent SR or confirmation that a statistically significant result is also clinically important. ${ }^{15}$ The priorities identified by the ADPSP were not all focused on treatment efficacy however, and we were unable to find guidance for other research questions. The complexity of the questions also made it difficult to apply definitions of uncertainty. The identified SRs also had multiple effect estimates within and across different outcomes, comparisons and populations. For example, 25 SRs relating to the exercise component of question seven (diet, exercise and depression development) identified four specific populations (teenagers, older adults, pregnant women, persons with chronic disease) and for question three part a (cost advantages for non-pharmacological treatment options), there were 22 different cost comparisons across 18 studies examining 16 different therapies. In order to answer whether treatment uncertainties exist, the question needed to be very specific with details on population, intervention, comparison and outcome. In addition, many of the questions had multiple components; therefore, at times there was evidence for some but not all components. For question seven, there was high quality evidence supporting exercise for preventing further development of depression symptoms; however, there was very little evidence regarding diet. The extensive volume of evidence also posed challenges. For example, question three, part c (effectiveness of non-pharmacological interventions) identified 179 SRs; given our short timeline, it was necessary to include only the 27 SRs which mostly directly answered the research question. An a priori process for ranking or further categorising large volumes of evidence is recommended.

\section{Lessons learnt}

The role of knowledge synthesis in PPSPs is currently not well defined. Detailed guidelines that outline how to balance efficiency and methodological rigour while 
determining the existing evidence base for a PPSP are needed. We recommend that knowledge synthesis experts be involved early in the PPSP process. Input into the survey may allow for more details of the populations, interventions, comparisons and outcomes of interest by both the public and the steering committee leading to more specific and answerable research questions. Development of very focused questions will decrease the time needed for literature screening and aid in defining criteria to determine certainty of evidence or KT needs a priori. Focused questions are also more likely to be incorporated into a research agenda, a core PPSP goal.

\section{Limitations}

With limited rapid review methods guidance available in 2017, we adapted methods used by the Canadian Agency for Drugs and Technologies in Health $(\mathrm{CADTH})^{16}$ and scoping review methodology. ${ }^{19}$ While the need for evidence in a short time frame directed our methods, our results should be interpreted in light of some limitations such as searching one database (PubMed), not including grey literature, and using a single experienced screener. According to scoping review methodology, ${ }^{19}$ we did not conduct formal quality assessment, rather we reported author-identified limitations of the included studies. Due to the large body of evidence, we filtered the citations using recognised approaches to hierarchies of evidence. We did not involve patients in reframing the questions or in identification and synthesis of relevant literature; this is consistent with existing guidance for PSPs. ${ }^{15}$ However, further work on whether and how to involve patients in this aspect of a PSP would be beneficial to ensure their perspectives are integrated throughout the process. Finally, the results of this PPSP may not be generalisable to other jurisdictions. For example, a PPSP was undertaken in the UK in 2014/2015 on the same topic of depression and a comparison with the resulting ten priorities revealed only two similar questions relating to the most successful treatment for depression and the impact on children of having a parent with depression. There were three different questions that addressed similar concepts: access to services, workplace stigma and the role of friends and family. ${ }^{173}$

\section{CONCLUSION}

Through 11 rapid responses, we identified an extensive body of evidence addressing patient identified priorities in depression research and identified the strengths and limitations of existing evidence, areas of uncertainty and general directions for future research. This work can serve as a strong foundation to guide future research and KT activities. Integrated knowledge syntheses bring value to the PPSP process and help avoid duplication of research effort. The role of knowledge synthesis in PPSPs is not well defined at present, in particular how to involve patients in this process. Categorising available evidence without focused questions or a priori criteria is challenging and may not support all PPSPs particularly where the scope of priorities is broad.

\section{Author affiliations}

${ }^{1}$ Alberta Strategy for Patient-Oriented Research (SPOR) SUPPORT Unit Knowledge Translation Platform, Department of Pediatrics, University of Alberta, Edmonton, Alberta, Canada

${ }^{2}$ Alberta Research Centre for Health Evidence, Department of Pediatrics, University of Alberta, Edmonton, Alberta, Canada

${ }^{3}$ Department of Psychiatry, University of Alberta, Edmonton, Alberta, Canada ${ }^{4}$ Alberta Strategy for Patient-Oriented Research (SPOR) SUPPORT Unit Patient Engagement Platform, University of Alberta, Edmonton, Alberta, Canada

Acknowledgements We would like to thank Samantha Guitard for assistance with formatting.

Contributors MS authored three of the rapid responses and was the main contributor to the manuscript. MG authored three of the rapid responses and had input into the manuscript. AG, MN and LMB each authored two of the rapid responses and had input into the manuscript. RMF developed and ran all the search strategies for the rapid responses and contributed the searching sections of the manuscript. LB and PM-L led the ADPSP and PM-L collaborated in adaptation of the identified priorities into research questions. LH initiated this collaborative manuscript and contributed to the writing. All authors read, revised and approved the final version of the paper.

Funding This work was supported by the Alberta Strategy for Patient- Oriented Research SUPPORT Unit Knowledge Translation Program, which is funded by Alberta Innovates and the Canadian Institutes of Health Research, and the Alberta Research Centre for Health Evidence.

Competing interests None declared.

Patient consent for publication Not required.

Provenance and peer review Not commissioned; externally peer reviewed.

Data sharing statement All data produced or analysed in this study are included in the manuscript and its appendices.

Open access This is an open access article distributed in accordance with the Creative Commons Attribution Non Commercial (CC BY-NC 4.0) license, which permits others to distribute, remix, adapt, build upon this work non-commercially, and license their derivative works on different terms, provided the original work is properly cited, appropriate credit is given, any changes made indicated, and the use is non-commercial. See: http://creativecommons.org/licenses/by-nc/4.0/.

\section{REFERENCES}

1. World Health Organization. Depression and other common mental disorders: global health estimates. Geneva: World Health Organization, 2017:1-24.

2. Kessler RC, Bromet EJ. The epidemiology of depression across cultures. Annu Rev Public Health 2013;34:119-38.

3. Evans-Lacko S, Knapp M. Global patterns of workplace productivity for people with depression: absenteeism and presenteeism costs across eight diverse countries. Soc Psychiatry Psychiatr Epidemiol 2016;51:1525-37.

4. Bouwmans CA, Vemer P, van Straten A, et al. Health-related quality of life and productivity losses in patients with depression and anxiety disorders. J Occup Environ Med 2014;56:420-4.

5. Sivertsen H, Bjørkløf GH, Engedal K, et al. Depression and quality of life in older persons: a review. Dement Geriatr Cogn Disord 2015;40(5-6):311-39.

6. Lépine JP, Gastpar M, Mendlewicz J, et al. Depression in the community: the first pan-European study DEPRES (Depression Research in European Society). Int Clin Psychopharmacol 1997;12:19-29.

7. Crowe S, Fenton M, Hall M, et al. Patients', clinicians' and the research communities' priorities for treatment research: there is an important mismatch. Res Involv Engagem 2015;1:2.

8. Canadian Institutes of Health Research. [Internet] Strategy for patient-oriented research: Government of Canada. http://www.cihrirsc.gc.ca/e/41204.html. (cited: 26 Apr 2018).

9. Patient-Centered Outcomes Research Institute [Internet]. http:// www.pcori.org (cited: 26 Apr 2018). 
10. James Lind Alliance. [Internet]. National Health Service. [cited: 26 Apr 2018]. http://www.jla.nihr.ac.uk

11. Tallon D, Chard J, Dieppe P. Relation between agendas of the research community and the research consumer. The Lancet 2000;355:2037-40.

12. Alberta Innovates. Internet] Alberta's top 11 priorities for depression research. Alberta Depression Research Priority Setting Project. https://albertainnovates.ca/our-health-innovation-focus/ the-alberta-spor-support-unit/patient-engagement-platform/ alberta-depression-research-priority-setting-project/ (cited: 26 Apr 2018).

13. Breault L, Rittenbach K, Hartle K, et al. People with lived experience (PWLE) of depression: describing and reflecting on an explicit patient engagement process within depression research priority setting in Alberta, Canada. Res Involv Engagem 2018;16:5.

14. Breault L, Rittenbach K, Hartle K, et al. A survey of priority setting for depression: eleven research questions asked by people with lived depression experience in Alberta. CMAJ Open 2018;6:E398-E405

15. Cowan $\mathrm{K}$, Oliver S. [Internet]. James Lind Alliance guidebook. Southampton, UK: The James Lind Alliance, 2016. Available from http://www.jla.nihr.ac.uk/jla-guidebook/.

16. Canadian Agency for Drugs and Technologies in Health. [Internet] Rapid response summary with critical appraisal: process. 2015;1 https://www.cadth.ca/sites/default/files/external_rr_12_12 5 process.pdf.

17. Harker J, Kleijnen J. What is a rapid review? A methodological exploration of rapid reviews in Health Technology Assessments. Int $J$ Evid Based Healthc 2012;10:397-410.

18. National Library of Medicine. [Internet]. MEDLINE: Description of the database. http://www.nlm.nih.gov/bsd/medline.html (cited 5 Mar 2019).

19. The Joanna Briggs Institute. The Joanna Briggs Institute reviewers' manual: 2015 edition / supplement. Australia: The Joanna Briggs Institute, 2015. Available from. www.joannabriggs.org.

20. Farah $\mathrm{WH}$, Alsawas M, Mainou M, et al. Non-pharmacological treatment of depression: a systematic review and evidence map. Evid Based Med 2016;21:214-21.

21. Gartlehner G, Gaynes BN, Amick HR, et al. AHRQ comparative effectiveness reviews. Nonpharmacological versus pharmacological treatments for adult patients with major depressive disorder. Rockville (MD): Agency for Healthcare Research and Quality (US), 2015.

22. Weitz ES, Hollon SD, Twisk J, et al. Baseline depression severity as moderator of depression outcomes between cognitive behavioral therapy vs pharmacotherapy. JAMA Psychiatry 2015;72:1102-9.

23. Trivedi RB, Nieuwsma JA, Williams JW Jr, et al. VA Evidence-based synthesis program reports. Evidence synthesis for determining the efficacy of psychotherapy for treatment resistant depression. Washington (DC: Department of Veterans Affairs (US), 2009.

24. Cox GR, Callahan P, Churchill R, et al. Psychological therapies versus antidepressant medication, alone and in combination for depression in children and adolescents. Cochrane Database Syst Rev 2014;11:Cd008324.

25. Biesheuvel-Leliefeld KE, Kok GD, Bockting CL, et al. Effectiveness of psychological interventions in preventing recurrence of depressive disorder: meta-analysis and meta-regression. J Affect Disord 2015;174:400-10

26. Guidi J, Fava GA, Fava M, et al. Efficacy of the sequential integration of psychotherapy and pharmacotherapy in major depressive disorder: a preliminary meta-analysis. Psychol Med 2011:41:321-31.

27. Chiesa A, Serretti A. Mindfulness based cognitive therapy for psychiatric disorders: a systematic review and meta-analysis. Psychiatry Res 2011;187:441-53.

28. Piet $\mathrm{J}$, Hougaard $\mathrm{E}$. The effect of mindfulness-based cognitive therapy for prevention of relapse in recurrent major depressive disorder: a systematic review and meta-analysis. Clin Psychol Rev $2011 ; 31: 1032-40$

29. Cox GR, Fisher CA, De Silva S, et al. Interventions for preventing relapse and recurrence of a depressive disorder in children and adolescents. Cochrane Database Syst Rev 2012;11:Cd007504.

30. Wu Q, Qu W, Crowell MD, et al. Tricyclic antidepressant use and risk of fractures: a meta-analysis of cohort and case-control studies. $J$ Bone Miner Res 2013;28:753-63.

31. Wu Q, Liu J, Gallegos-Orozco JF, et al. Depression, fracture risk, and bone loss: a meta-analysis of cohort studies. Osteoporos Int 2010;21:1627-35

32. Wu Q, Bencaz AF, Hentz JG, et al. Selective serotonin reuptake inhibitor treatment and risk of fractures: a meta-analysis of cohort and case-control studies. Osteoporos Int 2012;23:365-75.
33. Gebara MA, Shea ML, Lipsey KL, et al. Depression, antidepressants, and bone health in older adults: a systematic review. J Am Geriatr Soc 2014;62:1434-41.

34. Eom CS, Lee HK, Ye S, et al. Use of selective serotonin reuptake inhibitors and risk of fracture: a systematic review and metaanalysis. J Bone Miner Res 2012;27:1186-95.

35. Rotella F, Mannucci E. Depression as a risk factor for diabetes: a meta-analysis of longitudinal studies. J Clin Psychiatry 2013;74:31-7.

36. Correll CU, Detraux J, De Lepeleire J, et al. Effects of antipsychotics, antidepressants and mood stabilizers on risk for physical diseases in people with schizophrenia, depression and bipolar disorder. World Psychiatry 2015;14:119-36.

37. Pérez-Piñar $M$, Mathur $R$, Foguet $Q$, et al. Cardiovascular risk factors among patients with schizophrenia, bipolar, depressive, anxiety, and personality disorders. Eur Psychiatry 2016;35:8-15.

38. Rubin RR, Peyrot M, Gaussoin SA, et al. Four-year analysis of cardiovascular disease risk factors, depression symptoms, and antidepressant medicine use in the Look AHEAD (Action for Health in Diabetes) clinical trial of weight loss in diabetes. Diabetes Care 2013;36:1088-94.

39. Pocha C, Knott A, Rector TS, et al. Are selective serotonin reuptake inhibitors associated with hepatocellular carcinoma in patients with hepatitis C? J Clin Psychiatry 2014;75:e1122-e1126.

40. Egede LE, Gebregziabher M, Walker RJ, et al. Trajectory of cost overtime after psychotherapy for depression in older Veterans via telemedicine. J Affect Disord 2017;207:157-62.

41. Richards DA, Ekers D, McMillan D, et al. Cost and outcome of behavioural activation versus cognitive behavioural therapy for depression (COBRA): a randomised, controlled, non-inferiority trial. Lancet 2016;388:871-80.

42. Andersen $\mathrm{P}$, Toner $\mathrm{P}$, Bland $\mathrm{M}$, et al. Effectiveness of transdiagnostic cognitive behaviour therapy for anxiety and depression in adults: a systematic review and meta-analysis. Behav Cogn Psychother 2016;44:673-90.

43. Bower P, Knowles S, Coventry PA, et al. Counselling for mental health and psychosocial problems in primary care. Cochrane Database Syst Rev 2011;9:Cd001025.

44. Brown JS, Sellwood K, Beecham JK, et al. Outcome, costs and patient engagement for group and individual CBT for depression: a naturalistic clinical study. Behav Cogn Psychother 2011;39:355-8.

45. Goodyer IM, Reynolds S, Barrett B, et al. Cognitive-behavioural therapy and short-term psychoanalytic psychotherapy versus brief psychosocial intervention in adolescents with unipolar major depression (IMPACT): a multicentre, pragmatic, observer-blind, randomised controlled trial. Health Technol Assess 2017;21:1-94.

46. Hammond GC, Croudace TJ, Radhakrishnan M, et al. Comparative effectiveness of cognitive therapies delivered face-to-face or over the telephone: an observational study using propensity methods. PLoS One 2012;7:e42916.

47. Kafali N, Cook B, Canino G, et al. Cost-effectiveness of a randomized trial to treat depression among Latinos. J Ment Health Policy Econ 2014;17:41-50.

48. Karyotaki E, Tordrup D, Buntrock C, et al. Economic evidence for the clinical management of major depressive disorder: a systematic review and quality appraisal of economic evaluations alongside randomised controlled trials. Epidemiol Psychiatr Sci 2017;26:1-16.

49. Meuldijk D, Carlier IV, van Vliet IM, et al. Economic evaluation of concise cognitive behavioural therapy and/or pharmacotherapy for depressive and anxiety disorders. J Ment Health Policy Econ 2015:18:175-83.

50. Morrell C, Warner R, Slade P, et al. Psychological interventions for postnatal depression: cluster randomised trial and economic evaluation. The PoNDER trial. Health Technol Assess 2009;13:1-153.

51. Boudreau R, Moulton K, Cunningham J. Canadian Agency for Drugs and Technologies in Health (CADTH). Self-directed cognitive behavioural therapy for adults with diagnosis of depression: systematic review of clinical effectiveness, cost-effectiveness, and guidelines. CADTH Technol Overv 2010;1:e0125.

52. Romero-Sanchiz P, Nogueira-Arjona R, García-Ruiz A, et al. Economic evaluation of a guided and unguided internet-based CBT intervention for major depression: Results from a multi-center, three-armed randomized controlled trial conducted in primary care. PLoS One 2017;12:e0172741.

53. Solomon D, Proudfoot J, Clarke J, et al. e-CBT (myCompass), antidepressant medication, and face-to-face psychological treatment for depression in australia: a cost-effectiveness comparison. J Med Internet Res 2015;17:e255. 
54. Warmerdam L, Smit F, van Straten A, et al. Cost-utility and cost-effectiveness of internet-based treatment for adults with depressive symptoms: randomized trial. J Med Internet Res 2010;12:e53.

55. Berghout CC, Zevalkink J, Hakkaart-van Roijen L. A cost-utility analysis of psychoanalysis versus psychoanalytic psychotherapy. Int J Technol Assess Health Care 2010;26:3-10.

56. Dunn NJ, Rehm LP, Schillaci J, et al. A randomized trial of selfmanagement and psychoeducational group therapies for comorbid chronic posttraumatic stress disorder and depressive disorder. $J$ Trauma Stress 2007;20:221-37.

57. Maljanen $\mathrm{T}$, Knekt $\mathrm{P}$, Lindfors $\mathrm{O}$, et al. The cost-effectiveness of short-term and long-term psychotherapy in the treatment of depressive and anxiety disorders during a 5-year follow-up. J Affect Disord 2016;190:254-63.

58. Gertler P, Tate RL, Cameron ID. Non-pharmacological interventions for depression in adults and children with traumatic brain injury. Cochrane Database Syst Rev 2015;12:Cd009871.

59. Shinohara K, Honyashiki M, Imai H, et al. Behavioural therapies versus other psychological therapies for depression. Cochrane Database Syst Rev 2013;10:Cd008696.

60. Egede LE, Acierno R, Knapp RG, et al. Psychotherapy for depression in older veterans via telemedicine: a randomised, open-label, non-inferiority trial. Lancet Psychiatry 2015;2:693-701.

61. Merry SN, Stasiak K, Shepherd M, et al. The effectiveness of SPARX, a computerised self help intervention for adolescents seeking help for depression: randomised controlled non-inferiority trial. BMJ 2012;344:e2598

62. Berking $\mathrm{M}$, Ebert $\mathrm{D}$, Cuijpers $\mathrm{P}$, et al. Emotion regulation skills training enhances the efficacy of inpatient cognitive behaviora therapy for major depressive disorder: a randomized controlled trial. Psychother Psychosom 2013;82:234-45.

63. Goodyer IM, Reynolds S, Barrett B, et al. Cognitive behavioural therapy and short-term psychoanalytical psychotherapy versus a brief psychosocial intervention in adolescents with unipolar major depressive disorder (IMPACT): a multicentre, pragmatic, observerblind, randomised controlled superiority trial. Lancet Psychiatry 2017;4:109-19.

64. Himelhoch S, Medoff D, Maxfield J, et al. Telephone based cognitive behavioral therapy targeting major depression among urban dwelling, low income people living with HIV/AIDS: results of a randomized controlled trial. AIDS Behav 2013;17:2756-64.

65. Andersson G, Cuijpers P, Carlbring P, et al. Guided internet-based vs. face-to-face cognitive behavior therapy for psychiatric and somatic disorders: a systematic review and meta-analysis. World Psychiatry 2014;13:288-95.

66. Barth J, Munder T, Gerger H, et al. Comparative efficacy of seven psychotherapeutic interventions for patients with depression: a network meta-analysis. PLoS Med 2013;10:e1001454.

67. Braun SR, Gregor B, Tran US. Comparing bona fide psychotherapies of depression in adults with two meta-analytical approaches. PLoS One 2013;8:e68135.

68. Burlingame GM, Seebeck JD, Janis RA, et al. Outcome differences between individual and group formats when identical and nonidentical treatments, patients, and doses are compared: a 25year meta-analytic perspective. Psychotherapy 2016;53:446-61.

69. Cape J, Whittington C, Buszewicz M, et al. Brief psychological therapies for anxiety and depression in primary care: meta-analysis and meta-regression. BMC Med 2010;8:38.

70. Cuijpers P, Andersson G, Donker T, et al. Psychological treatment of depression: results of a series of meta-analyses. Nord J Psychiatry 2011;65:354-64.

71. Cuijpers P, Donker T, van Straten A, et al. Is guided self-help as effective as face-to-face psychotherapy for depression and anxiety disorders? A systematic review and meta-analysis of comparative outcome studies. Psychol Med 2010;40:1943-57.

72. Cuijpers P, van Straten A, Andersson G, et al. Psychotherapy for depression in adults: a meta-analysis of comparative outcome studies. J Consult Clin Psychol 2008;76:909-22.

73. Dedert E, McDuffie JR, Swinkels C, et al. VA evidence-based synthesis program reports. Computerized cognitive behavioral therapy for adults with depressive or anxiety disorders. Washington (DC): Department of Veterans Affairs (US), 2013.

74. Dennis CL, Hodnett E. Psychosocial and psychological interventions for treating postpartum depression. Cochrane Database Syst Rev 2007;4:Cd006116.

75. Hazell P. Depression in children and adolescents. BMJ Clin Evid 2011;2011:1008.

76. Henken HT, Huibers MJ, Churchill R, et al. Family therapy for depression. Cochrane Database Syst Rev 2007;3:Cd006728.
77. Hunot V, Moore TH, Caldwell DM, et al. 'Third wave' cognitive and behavioural therapies versus other psychological therapies for depression. Cochrane Database Syst Rev 2013;10:Cd008704.

78. Jakobsen JC, Hansen JL, Simonsen S, et al. Effects of cognitive therapy versus interpersonal psychotherapy in patients with major depressive disorder: a systematic review of randomized clinical trials with meta-analyses and trial sequential analyses. Psychol Med 2012;42:1343-57

79. Jorm AF, Morgan AJ, Hetrick SE. Relaxation for depression. Cochrane Database Syst Rev 2008;4:Cd007142.

80. Kriston L, von Wolff $A$, Westphal $A$, et al. Efficacy and acceptability of acute treatments for persistent depressive disorder: a network meta-analysis. Depress Anxiety 2014;31:621-30.

81. Linde K, Rücker G, Sigterman K, et al. Comparative effectiveness of psychological treatments for depressive disorders in primary care: network meta-analysis. BMC Fam Pract 2015;16:103.

82. Montgomery EC, Kunik ME, Wilson N, et al. Can paraprofessionals deliver cognitive-behavioral therapy to treat anxiety and depressive symptoms? Bull Menninger Clin 2010;74:45-62.

83. Nieuwenhuijsen K, Bultmann U, Neumeyer-Gromen A, et al. Interventions to improve occupational health in depressed people. Cochrane Database Syst Rev 2008;2:Cd006237.

84. Samad Z, Brealey S, Gilbody S. The effectiveness of behavioural therapy for the treatment of depression in older adults: a metaanalysis. Int J Geriatr Psychiatry 2011;26:1211-20.

85. Spielmans GI, Pasek LF, McFall JP. What are the active ingredients in cognitive and behavioral psychotherapy for anxious and depressed children? A meta-analytic review. Clin Psychol Rev 2007;27:642-54.

86. Steinert C, Munder T, Rabung S, et al. Psychodynamic therapy: As efficacious as other empirically supported treatments? A meta-analysis testing equivalence of outcomes. Am J Psychiatry 2017; 174:943-53.

87. Tolin DF. Is cognitive-behavioral therapy more effective than other therapies? A meta-analytic review. Clin Psychol Rev 2010;30:710-20.

88. Wilson KC, Mottram PG, Vassilas CA. Psychotherapeutic treatments for older depressed people. Cochrane Database Syst Rev 2008;1:Cd004853.

89. Zhou X, Hetrick SE, Cuijpers P, et al. Comparative efficacy and acceptability of psychotherapies for depression in children and adolescents: a systematic review and network meta-analysis. World Psychiatry 2015;14:207-22.

90. Bennett K, Rhodes AE, Duda S, et al. A youth suicide prevention plan for Canada: a systematic review of reviews. Can J Psychiatry 2015;60:245-57.

91. Das JK, Salam RA, Lassi ZS, et al. Interventions for adolescent mental health: an overview of systematic reviews. J Adolesc Health 2016;59:S49-S60.

92. Devenish B, Berk L, Lewis AJ. The treatment of suicidality in adolescents by psychosocial interventions for depression: a systematic literature review. Aust N Z J Psychiatry 2016;50:726-40.

93. Hawton K, Witt KG, Taylor Salisbury TL, et al. Interventions for self-harm in children and adolescents. Cochrane Database Syst Rev 2015;12:Cd012013.

94. Katz C, Bolton SL, Katz LY, et al. A systematic review of schoolbased suicide prevention programs. Depress Anxiety 2013;30:n/ a-45.

95. Perry $\mathrm{Y}$, Werner-Seidler A, Calear AL, et al. Web-based and mobile suicide prevention interventions for young people: a systematic review. J Can Acad Child Adolesc Psychiatry 2016;25:73-9.

96. Pu J, Zhou X, Liu L, et al. Efficacy and acceptability of interpersonal psychotherapy for depression in adolescents: a meta-analysis of randomized controlled trials. Psychiatry Res 2017;253:226-32.

97. Townsend E, Walker DM, Sargeant S, et al. Systematic review and meta-analysis of interventions relevant for young offenders with mood disorders, anxiety disorders, or self-harm. J Adolesc 2010;33:9-20.

98. Cuijpers P, de Beurs DP, van Spijker BA, et al. The effects of psychotherapy for adult depression on suicidality and hopelessness: a systematic review and meta-analysis. J Affect Disord 2013;144:183-90.

99. Hawton K, Witt KG, Salisbury TLT, et al. Psychosocial interventions following self-harm in adults: a systematic review and metaanalysis. Lancet Psychiatry 2016;3:740-50.

100. Hawton K, Witt KG, Taylor Salisbury TL, et al. Psychosocial interventions for self-harm in adults. Cochrane Database Syst Rev 2016;5:Cd012189.

101. Jakobsen JC, Hansen JL, Storebø OJ, et al. The effects of cognitive therapy versus 'no intervention' for major depressive disorder. PLOS One 2011;6:e28299. 
102. Lapierre S, Erlangsen A, Waern M, et al. A systematic review of elderly suicide prevention programs. Crisis 2011;32:88-98.

103. Okolie C, Dennis M, Simon Thomas E, et al. A systematic review of interventions to prevent suicidal behaviors and reduce suicidal ideation in older people. Int Psychogeriatr 2017;29:1801-24

104. Berrouiguet S, Baca-García E, Brandt S, et al. Fundamentals for future mobile-health (mhealth): a systematic review of mobile phone and web-based text messaging in mental health. $J$ Med Internet Res 2016;18:e135.

105. Fountoulakis KN, Gonda X, Siamouli M, et al. Psychotherapeutic intervention and suicide risk reduction in bipolar disorder: a review of the evidence. J Affect Disord 2009;113(1-2):21-9.

106. Meerwijk EL, Parekh A, Oquendo MA, et al. Direct versus indirect psychosocial and behavioural interventions to prevent suicide and suicide attempts: a systematic review and meta-analysis. Lancet Psychiatry 2016;3:544-54.

107. O'Connor E, Gaynes BN, Burda BU, et al. Screening for and treatment of suicide risk relevant to primary care: a systematic review for the U.S. Preventive Services Task Force. Ann Intern Med 2013:158:741-54.

108. van der Feltz-Cornelis CM, Sarchiapone M, Postuvan V, et al. Best practice elements of multilevel suicide prevention strategies: a review of systematic reviews. Crisis 2011;32:319-33.

109. Zalsman G, Hawton K, Wasserman D, et al. Suicide prevention strategies revisited: 10-year systematic review. Lancet Psychiatry 2016;3:646-59.

110. Lang UE, Beglinger $C$, Schweinfurth $N$, et al. Nutritional aspects of depression. Cell Physiol Biochem 2015;37:1029-43.

111. Williamson C. Dietary factors and depression in older people. $\mathrm{Br} \mathrm{J}$ Community Nurs 2009;14:422-6.

112. Chang SC, Cassidy A, Willett WC, et al. Dietary flavonoid intake and risk of incident depression in midlife and older women. Am J Clin Nutr 2016;104:704-14.

113. Chocano-Bedoya PO, O'Reilly EJ, Lucas M, et al. Prospective study on long-term dietary patterns and incident depression in middleaged and older women. Am J Clin Nutr 2013;98:813-20.

114. Colangelo LA, He K, Whooley MA, et al. Higher dietary intake of long-chain omega-3 polyunsaturated fatty acids is inversely associated with depressive symptoms in women. Nutrition 2009;25:1011-9.

115. Gopinath B, Flood VM, Burlutksy G, et al. Association between carbohydrate nutrition and prevalence of depressive symptoms in older adults. Br J Nutr 2016;116:2109-14.

116. Gougeon L, Payette H, Morais J, et al. Dietary patterns and incidence of depression in a cohort of community-dwelling older Canadians. J Nutr Health Aging 2015;19:431-6.

117. Lehto SM, Ruusunen A, Tolmunen T, et al. Dietary zinc intake and the risk of depression in middle-aged men: a 20 -year prospective follow-up study. J Affect Disord 2013;150:682-5.

118. Li Y, Dai Q, Ekperi LI, et al. Fish consumption and severely depressed mood, findings from the first national nutrition follow-up study. Psychiatry Res 2011;190:103-9.

119. Lucas M, Mirzaei F, O'Reilly EJ, et al. Dietary intake of $n-3$ and $n-6$ fatty acids and the risk of clinical depression in women: a 10-y prospective follow-up study. Am J Clin Nutr 2011;93:1337-43.

120. Oddy WH, Hickling S, Smith MA, et al. Dietary intake of omega-3 fatty acids and risk of depressive symptoms in adolescents. Depress Anxiety 2011;28:582-8.

121. Perez-Cornago A, Sanchez-Villegas A, Bes-Rastrollo M, et al. Relationship between adherence to dietary approaches to stop hypertension (DASH) diet indices and incidence of depression during up to 8 years of follow-up. Public Health Nutr 2017;20:2383-92.

122. Sánchez-Villegas A, Delgado-Rodríguez M, Alonso A, et al. Association of the Mediterranean dietary pattern with the incidence of depression: the Seguimiento Universidad de Navarra/ University of Navarra follow-up (SUN) cohort. Arch Gen Psychiatry 2009;66:1090-8.

123. Sánchez-Villegas $A$, Henríquez-Sánchez $P$, Ruiz-Canela M, et al. A longitudinal analysis of diet quality scores and the risk of incident depression in the SUN Project. BMC Med 2015;13:197.

124. Sánchez-Villegas A, Verberne L, De Irala J, et al. Dietary fat intake and the risk of depression: the SUN Project. PLoS One 2011;6:e16268.

125. Carter T, Morres ID, Meade O, et al. The effect of exercise on depressive symptoms in adolescents: a systematic review and meta-analysis. J Am Acad Child Adolesc Psychiatry 2016;55:580-90.

126. Cooney GM, Dwan K, Greig CA, et al. Exercise for depression. Cochrane Database Syst Rev 2013;9:Cd004366.
127. Danielsson L, Noras AM, Waern M, et al. Exercise in the treatment of major depression: a systematic review grading the quality of evidence. Physiother Theory Pract 2013;29:573-85.

128. de Souza Moura AM, Lamego MK, Paes F, et al. Comparison among aerobic exercise and other types of interventions to treat depression: a systematic review. CNS Neurol Disord Drug Targets 2015:14:1171-83

129. García-Toro M, Ibarra O, Gili M, et al. Four hygienic-dietary recommendations as add-on treatment in depression: a randomized-controlled trial. J Affect Disord 2012;140:200-3.

130. Gartlehner G, Gaynes BN, Amick HR, et al. Comparative benefits and harms of antidepressant, psychological, complementary, and exercise treatments for major depression: an evidence report for a clinical practice guideline from the american college of physicians. Ann Intern Med 2016;164:331-41.

131. Hearing CM, Chang WC, Szuhany KL, et al. Physical exercise for treatment of mood disorders: a critical review. Curr Behav Neurosci Rep 2016;3:350-9.

132. Herring MP, Puetz TW, O'Connor PJ, et al. Effect of exercise training on depressive symptoms among patients with a chronic illness: a systematic review and meta-analysis of randomized controlled trials. Arch Intern Med 2012;172:101-11.

133. Josefsson T, Lindwall M, Archer T. Physical exercise intervention in depressive disorders: meta-analysis and systematic review. Scand J Med Sci Sports 2014;24:259-72.

134. Knapen J, Vancampfort D, Moriën Y, et al. Exercise therapy improves both mental and physical health in patients with major depression. Disabil Rehabil 2015;37:1490-5.

135. Kvam S, Kleppe CL, Nordhus IH, et al. Exercise as a treatment for depression: a meta-analysis. J Affect Disord 2016;202:67-86.

136. Meekums B, Karkou V, Nelson EA. Dance movement therapy for depression. Cochrane Database Syst Rev 2015;2:Cd009895.

137. Mura G, Carta MG. Physical activity in depressed elderly. A systematic review. Clin Pract Epidemiol Ment Health 2013;9:125-35.

138. Mura G, Moro MF, Patten SB, et al. Exercise as an add-on strategy for the treatment of major depressive disorder: a systematic review. CNS Spectr 2014;19:496-508.

139. Netz Y. Is the comparison between exercise and pharmacologic treatment of depression in the clinical practice guideline of the american college of physicians evidence-based? Front Pharmacol 2017:8:257.

140. Park SC, Oh HS, Oh DH, et al. Evidence-based, nonpharmacological treatment guideline for depression in Korea. $J$ Korean Med Sci 2014;29:12-22.

141. Qaseem A, Barry MJ, Kansagara D. Clinical Guidelines Committee of the American College of Physicians. Nonpharmacologic versus pharmacologic treatment of adult patients with major depressive disorder: a clinical practice guideline from the American College of Physicians. Ann Intern Med 2016:164:350-9.

142. Radovic S, Gordon MS, Melvin GA. Should we recommend exercise to adolescents with depressive symptoms? A meta-analysis. $J$ Paediatr Child Health 2017:53:214-20.

143. Ranjbar E, Memari AH, Hafizi S, et al. Depression and exercise: a clinical review and management guideline. Asian J Sports Med 2015;6:e24055

144. Ravindran AV, da Silva TL. Complementary and alternative therapies as add-on to pharmacotherapy for mood and anxiety disorders: a systematic review. J Affect Disord 2013;150:707-19.

145. Ravindran AV, Lam RW, Filteau MJ, et al. Canadian Network for Mood and Anxiety Treatments (CANMAT) Clinical guidelines for the management of major depressive disorder in adults. V. Complementary and alternative medicine treatments. J Affect Disord 2009;117 Suppl 1:S54-S64.

146. Rethorst CD, Trivedi MH. Evidence-based recommendations for the prescription of exercise for major depressive disorder. J Psychiatr Pract 2013;19:204-12.

147. Rhyner KT, Watts A. Exercise and depressive symptoms in older adults: a systematic meta-analytic review. J Aging Phys Act 2016;24:234-46.

148. Schuch FB, Vancampfort D, Richards J, et al. Exercise as a treatment for depression: a meta-analysis adjusting for publication bias. J Psychiatr Res 2016;77:42-51.

149. Schuch FB, Vancampfort D, Rosenbaum S, et al. Exercise for depression in older adults: a meta-analysis of randomized controlled trials adjusting for publication bias. Braz $J$ Psychiatry 2016;38:247-54.

150. Serrano Ripoll MJ, Oliván-Blázquez B, Vicens-Pons E, et al. Lifestyle change recommendations in major depression: do they work? J Affect Disord 2015;183:221-8.

151. Shivakumar G, Brandon AR, Snell PG, et al. Antenatal depression: a rationale for studying exercise. Depress Anxiety 2011;28:234-42. 
152. Goodman SH, Rouse MH, Connell AM, et al. Maternal depression and child psychopathology: a meta-analytic review. Clin Child Fam Psychol Rev 2011;14:1-27.

153. Sanger C, lles JE, Andrew CS, et al. Associations between postnatal maternal depression and psychological outcomes in adolescent offspring: a systematic review. Arch Womens Ment Health 2015;18:147-62.

154. Sui G, Pan B, Liu G, et al. The long-term effects of maternal postnatal depression on a child's intelligence quotient: a metaanalysis of prospective cohort studies based on 974 cases. J Clin Psychiatry 2016;77:e1474-e82.

155. Lampard AM, Franckle RL, Davison KK. Maternal depression and childhood obesity: a systematic review. Prev Med 2014;59:60-7.

156. Hendricks K, Liu J. Childbearing depression and childhood aggression: literature review. MCN Am J Matern Child Nurs 2012;37:253-61.

157. Correia LL, Linhares MB. Maternal anxiety in the pre- and postnatal period: a literature review. Rev Lat Am Enfermagem 2007;15:677-83.

158. Waters CS, Hay DF, Simmonds JR, et al. Antenatal depression and children's developmental outcomes: potential mechanisms and treatment options. Eur Child Adolesc Psychiatry 2014;23:957-71.

159. Joyce $\mathrm{S}$, Modini M, Christensen $\mathrm{H}$, et al. Workplace interventions for common mental disorders: a systematic meta-review. Psychol Med 2016;46:683-97.

160. Tan L, Wang MJ, Modini M, et al. Preventing the development of depression at work: a systematic review and meta-analysis of universal interventions in the workplace. BMC Med 2014;12:74.

161. Chu AH, Koh D, Moy FM, et al. Do workplace physical activity interventions improve mental health outcomes? Occup Med 2014;64:235-45.

162. Dietrich S, Deckert S, Ceynowa M, et al. Depression in the workplace: a systematic review of evidence-based prevention strategies. Int Arch Occup Environ Health 2012;85:1-11.
163. Martin A, Sanderson K, Cocker F. Meta-analysis of the effects of health promotion intervention in the workplace on depression and anxiety symptoms. Scand J Work Environ Health 2009;35:7-18.

164. Nieuwenhuijsen $\mathrm{K}$, Faber B, Verbeek JH, et al. Interventions to improve return to work in depressed people. Cochrane Database Syst Rev 2014;3:CD006237.

165. Furlan AD, Gnam WH, Carnide N, et al. Systematic review of intervention practices for depression in the workplace. J Occup Rehabil 2012;22:312-21.

166. Cousins L, Goodyer IM. Antidepressants and the adolescent brain. $J$ Psychopharmacol 2015;29:545-55.

167. Tao R, Calley CS, Hart J, et al. Brain activity in adolescent major depressive disorder before and after fluoxetine treatment. $A m \mathrm{~J}$ Psychiatry 2012;169:381-8.

168. Brady P, Kangas M, McGill K. "Family matters": a systematic review of the evidence for family psychoeducation for major depressive disorder. J Marital Fam Ther 2017;43:245-63.

169. Meis LA, Griffin JM, Greer N, et al. Couple and family involvement in adult mental health treatment: a systematic review. Clin Psychol Rev 2013;33:275-86.

170. Stahl ST, Rodakowski J, Saghafi EM, et al. Systematic review of dyadic and family-oriented interventions for late-life depression. Int $J$ Geriatr Psychiatry 2016;31:963.

171. Vallury KD, Jones M, Gray R. Do family-oriented interventions reduce poststroke depression? A systematic review and recommendations for practice. Top Stroke Rehabil 2015;22:453-9.

172. Wang F, Luo D, Fu L, et al. The efficacy of couple-based interventions on health-related quality of life in cancer patients and their spouses: a meta-analysis of 12 randomized controlled trials. Cancer Nurs 2017;40:39-47.

173. MQ: Transforing mental health. [Internet]. Depression:asking the right questions. 2016 http://www.jla.nihr.ac.uk/priority-settingpartnerships/depression/downloads/Depression-PSP-final-report. pdf (cited 22 Feb 2019). 